\title{
Chemical composition and oxidative evolution of Sacha Inchi (Plukentia volubilis L.) oil from Xishuangbanna (China)
}

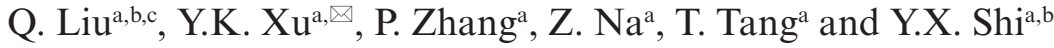 \\ aCAS Key Laboratory of Tropical Plant Resource and Sustainable Use, Xishuangbanna Tropical Botanical Garden, \\ Chinese Academy of Sciences, Menglun, Mengla, Yunnan 666303, PR China \\ ${ }^{b}$ University of Chinese Academy of Sciences, Beijing 100049, PR China \\ ${ }^{\mathrm{c}}$ CAS Key Laboratory of Tropical Forest Ecology, Xishuangbanna Tropical Botanical Garden, Chinese Academy of \\ Sciences, Menglun, Mengla, Yunnan 666303, PR China \\ Corresponding author: xyk@xtbg.ac.cn
}

Submitted: 29 July 2013; Accepted: 28 October 2013; Published on line: 13/02/2014

SUMMARY: Sacha Inchi oil was studied for its physicochemical characteristics, chemical composition, radical scavenging activity and storage stability. The fatty acid composition was studied by gas chromatography-flame ionization (GC-FID) and the analysis showed that the oil is highly enriched in $\alpha$-linolenic (43.5\%) and linoleic $(39.6 \%)$ acids. The tocopherol content in the oil analyzed by high performance liquid chromatography/ ultraviolet-visible detector (HPLC/UV-VIS) was also high (161.87 mg.100 g $\mathrm{g}^{-1}$ ). Both DPPH and ABTS assays detected relatively high radical scavenging activity. After twelve months of storage, the oil showed relatively good storage stability. The results will help guide further investigation of the health benefits of Sacha Inchi oil for the population and the development of better edible oil products and nutraceuticals.

KEYWORDS: Antioxidant capacity; Chemical composition; Omega-3; Physicochemical characteristics; Sacha Inchi; Storage stability

RESUMEN: Composición química y evolución oxidativa del aceite de Sacha Inchi (Plukentia volubilis L.) de Xishuangbanna (China). Se ha estudiado las características físico-químicas, la actividad de captación de radicales y la estabilidad durante el almacenamiento de aceites de sacha inchi. La composición en ácidos grasos se estudió mediante cromatografía de gases (GC-FID) y mostró que el aceite es altamente rico en $\alpha$-linolénico $(43,5 \%)$ y linoleico $(39,6 \%)$. El contenido de tocoferoles analizado mediante cromatografía líquida y detección mediante ultravioleta-visible (HPLC/UV-VIS) fue alto (161,87 mg.100 g $\mathrm{g}^{-1}$. Los ensayos de DPPH y ABTS detectaron actividad captadora de radicales relativamente alta. Tras doce meses de almacenamiento los aceites mostraron una relativamente buena estabilidad. Los resultados ayudarán a orientar investigación adicional sobre los beneficios para la salud del aceite de Sacha Inchi para la población y al desarrollo de mejores productos de aceites comestibles y nutracéuticos.

PALABRAS CLAVE: Capacidad antioxidante; Características físico-químicas; Composición química; Estabilidad de almacenamiento; Omega-3; Sacha Inchi

Citation/Cómo citar este artículo: Liu Q, Xu YK, Zhang P, Na Z, Tang T, Shi YX. 2014. Chemical composition and oxidative evolution of Sacha Inchi (Plukentia volubilis L.) oil from Xishuangbanna (China). Grasas Aceites 65 (1): e012. doi: http://dx.doi.org/10.3989/gya.075713.

Copyright: (C) 2014 CSIC. This is an open-access article distributed under the terms of the Creative Commons Attribution-Non Commercial (by-nc) Spain 3.0 Licence. 


\section{INTRODUCTION}

Sacha Inchi (Plukenetia volubilis Linneo), also known as "Inca peanut" or "mountain peanut", is a plant that is native to the Peruvian tropical jungles of South America at altitudes between 200 and $1500 \mathrm{~m}$ (Semino et al., 2008). The flour and oil from the seeds are traditionally consumed by the Indians of Peru to prepare various meals. Because it is not a cultivated crop, comprehensive studies on the nutritional value of Sacha Inchi seeds have only recently been of interest. The Chemical characterization has shown that the seeds have high protein $(33 \%)$ and oil (49\%) contents (Do Prado et al., 2011; Hamaker et al., 1992; Krivankova et al., 2007). Nutritional studies have provided evidence of health benefits associated with the intake of Sacha Inchi oil. Sacha Inchi oil not only lowers serum triglyceride and cholesterol but also decreases oxidative stress biomarkers (Cai et al., 2011). Sacha Inchi oil is of particular interest due to its high levels of omega-3 $(\omega-3)$ and omega-6 $(\omega-6)$ fatty acids, namely, $\alpha-$ lenolenic and $\alpha$-lenoleic (Guillén et al., 2003; Fanali et al., 2011). $\omega-3$ and $\omega-6$ polyunsaturated fatty acids are essential fatty acids which provide important health benefits to humans. There is increasing study on the fortification of food products with $\omega-6$ polyunsaturated fatty acids ( $\omega-6$ PUFAs) and especially $\omega-3$ polyunsaturated fatty acids $(\omega-3$ PUFAs). The $\omega-3$ PUFAs decrease inflammatory markers, blood pressure and triglycerides, which are established risk factors for cardiovascular disease (Pietrowski et al., 2011; Rymer and Givens, 2005). $\mathrm{Ni}$-Eidhin et al. (2003) provided a comprehensive review of the health benefits associated with $\omega-3$ PUFAs differentiating specific $\alpha$-linolenic (ALA, C18:3, $\omega-3$ ), eicosapentaenoic (EPA, 20:5, $\omega-3$ ) and docosahexaenoic (DHA, 22:6, $\omega-3$ ) acids and demonstrated that EPA and DHA can be produced in humans by the sequential elongation and desaturation of ALA. Considering the important physiological functions of $\omega-3$ PUFAs, dietary intake of these long-chain fatty acids is indispensable. Fish oil is the primary source of these essential polyunsaturated fatty acids as it contains $\omega-6\left(0.9-12 \mathrm{~g}^{-100 \mathrm{~g}^{-1}}\right.$ oil) and $\omega-3$ (11.9-35.3 g.100 g ${ }^{-1}$ oil) (VenegasCaleron et al., 2010; Rubio-Rodriguez et al., 2010). However, over-fishing, environmental pollution and a costly manufacturing process have resulted in fish oil not being the optimal choice nowadays. As the interest in looking for alternative plant-based $\omega-3$ fatty acids for better nutrition is growing worldwide, the demand for products developed from Sacha Inchi seeds and oil as $\omega-3$ fatty acid enriched food products or nutraceuticals continues to rise (Maurer et al., 2012).

Sacha Inchi was introduced to Xishuangbanna in 2006. Xishuangbanna lies between $21^{\circ} 08^{\prime} \mathrm{N}$ and $22^{\circ} 36^{\prime} \mathrm{N}, 99^{\circ} 56^{\prime} \mathrm{E}$ and $101^{\circ} 50^{\prime} \mathrm{E}$, located in the southwestern Yunnan Province of China; it is a mountainous area and has the only tropical rainforest in China. Its elevation ranges from $491 \mathrm{~m}$ at the bottom of the lowest valley in the south (Mekong River) to $2429.5 \mathrm{~m}$ at the top of the mountains in the north. It is a biodiversity hotspot and is rich in tropical plant resources (Cao et al., 2006; Myers et al., 2000). Several rare medicinal herbs used for traditional Chinese medicine are found only in this area. Sacha Inchi has adapted well to the area since its introduction and is currently being cultivated at a large scale as a promising oilseed crop to partly replace rubber (Cai et al., 2011; Cai et al., 2012). A nutritional evaluation of Sacha Inchi seeds harvested in Xishuangbanna has shown that they have a similar composition to those from Peru (Hamaker et al., 1992; Cai et al., 2011). The seeds also have high contents of protein and oil. Moreover, the seeds are enriched in $\alpha$-linolenic and linoleic acids (Cai et al., 2011). In this study, we evaluated the physicochemical characteristics and chemical composition of the oil. In addition, we evaluated the radical scavenging activity and the oxidative stability of the oil for the first time. This initial characterization will serve as the basis for the future development of Sacha Inchi oil as a nutraceutical and for further investigation of the health benefits of the oil.

\section{MATERIALS AND METHODS}

\subsection{Chemical}

Acetonitrile for HPLC analyses was purchased from Merck Chemical Co. (NJ, USA). 2, 2-Azobis-3ethylbenzthiazoline-6-sulphonic acid (ABTS) was purchased from Bio Basic Inc. (Markham, Ontario, Canada). Folin-Ciocalteu phenol reagent, $\alpha, \alpha-$ diphenyl- $\beta$-picrylhydrazyl (DPPH), $\alpha-, \gamma-$ and $\delta-$ Tocopherol standards were purchased from Sigma Chemical Co., (St. Louis, MO, USA). Boron trifluoride-methanol, hexane, potassium hydroxide and other chemicals were purchased from Sinopharm Chemical Reagent Co., Ltd. (Shanghai, China). All reagents were of analytical grade and the Methanol for HPLC was of chromatographic grade.

\subsection{Samples}

The seeds of Sacha Inchi were harvested from Xishuangbanna at optimum maturity, dried in the shade, and stored in $10 \mathrm{~kg}$ bags in a dark room at room temperature for later pressing. Oil samples were obtained by cold-pressing raw de-hulled seeds, using a screw press (KOMET, DD85G, German) in a warm press procedure at $50{ }^{\circ} \mathrm{C}$. The extracted oil was decanted into dark bottles and stored at $-20^{\circ} \mathrm{C}$ until analysis. 


\subsection{Physicochemical Characteristics}

The physicochemical characteristics of the oil samples were tested using the official American Oil Chemicals' Society methodology including acid value (Ca 5a-40); peroxide value (Cd 8-53); saponification value (Cd 3-25); iodine value (Cd 1-25); unsaponifiable matter (Ca 6a-40); moisture and volatile compound contents $(\mathrm{Ca} 2 \mathrm{c}-25)$; insoluble impurities $(\mathrm{Ca}$ 3a-46); refractive index (Cc 7-25); specific extinction (Ch 5-91) (AOCS, 2009). The oil characterization analyses were performed in duplicate.

\subsection{Fatty acid composition}

The fatty acid composition of the oil was analyzed by gas chromatography with a flame ionization detector (GC-FID) following Fanali et al. (2011). The fatty acids were converted into their methyl esters (FAMEs) by adding $2 \mathrm{~mL}$ of sodium methylate in methanol $\left(2.5 \mathrm{~mol} \cdot \mathrm{L}^{-1}\right)$ to $100 \mathrm{mg}$ of oil and incubating at $100^{\circ} \mathrm{C}$ for $15 \mathrm{~min}$. After the mixture was cooled, $1 \mathrm{~mL}$ of boron trifluoride-methanol $\left(20 \% \mathrm{BF}_{3}\right)$ reagent was added, and the solution was heated at $100{ }^{\circ} \mathrm{C}$ for $15 \mathrm{~min}$. The solution was then cooled and mixed with $1 \mathrm{~mL}$ of $\mathrm{n}$-hexane and $1 \mathrm{~mL}$ of water prior to being centrifuged for $2 \mathrm{~min}$ $(1300 \mathrm{rpm})$. The upper layer containing FAMEs was transferred to a $2 \mathrm{~mL}$ vial and stored at $4{ }^{\circ} \mathrm{C}$ until GC-FID analysis (Christie, 2003).

The analysis was carried out on an Agilent-6820 gas chromatograph with a manual injector, and FID detector. FAMEs separation was performed on Agilent J\&W GC columns (DBFFAP; $30 \mathrm{~m}$ long $\times$ $0.25 \mathrm{~mm}$ internal diameter, $0.25 \mu \mathrm{m}$ film thickness) and gas $(\mathrm{He})$ was used as a carrier at a constant flow of $1.2 \mathrm{~mL} \cdot \mathrm{min}^{-1}$. Oven temperatures were set at $180{ }^{\circ} \mathrm{C}$ and $220^{\circ} \mathrm{C}$ for start and end points, respectively, and increased at a rate of $10{ }^{\circ} \mathrm{C} \cdot \mathrm{min}^{-1}$ and held for $5 \mathrm{~min}$. The injector and detector temperatures were set at $260{ }^{\circ} \mathrm{C}$. The sample size was $1 \mathrm{~mL}$ with a split ratio of $30: 1$. For each sample triplicates were prepared and injected. Data analysis was carried out using Agilent Cerity software.

\subsection{Tocopherol composition}

The content of tocopherols in Sacha Inchi oil was analyzed using a High Performance Liquid Chromatography/ultraviolet-visible detector (HPLC/UV-VIS) according to a slightly modified method described by Gimeno et al. (2000). The sample was prepared by dissolving $1 \mathrm{~g}$ of oil in 1 $\mathrm{mL}$ of $\mathrm{n}$-hexane. The dissolved oil samples were run on an Agilent 1100 chromatographic system with a quaternary pump (G1311A), an autosampler (G1313A), a degasser (G1322A), and a dual absorbance detector (G1315B). The chromatographic data were acquired and processed using the software package Agilent. The analytical column was Agilent Zorbax SB C-18 $(4.6 \times 250 \mathrm{~mm}$ and particle size of 5 $\mu \mathrm{m})$ from Agela Technologies.

All of the analyses were performed at ambient temperature. The mobile phase was a mixture of acetonitrile-deionized water $(98: 2, \mathrm{vol} / \mathrm{vol})$, and the absorption wavelength in the UV detector was $292 \mathrm{~nm}$. Samples with $3 \mu \mathrm{L}$ volume and a flow ratio of $1 \mathrm{~mL} \cdot \mathrm{min}^{-1}$ were used for analysis. The amount of each compound, namely $\alpha$-tocopherol, $\gamma$-tocopherol, and $\delta$-tocopherol, was calculated from the results obtained for each standard.

\subsection{Total phenols}

The analysis of total phenolic compounds was performed using the Folin-Ciocalteu spectrophotometric method described by Hrncirik and Fritsche (2004). Briefly, a sample of $2.5 \mathrm{~g}$ oil was first dissolved in $5 \mathrm{~mL}$ hexane then extracted with methanol/water $(80: 20, \mathrm{v} / \mathrm{v})$ for 2 min under nitrogen atmosphere with an electronic blender. Phase separation was achieved by centrifugation for $20 \mathrm{~min}$ at $4000 \mathrm{rpm}$. The extraction procedure was repeated twice, the two methanolic fractions were pooled and stored at $-20^{\circ} \mathrm{C}$ until analysis. A $2 \mathrm{~mL}$ aliquot of the methanolic phase was diluted with water to a total volume of $5 \mathrm{~mL}$ followed by an addition of $0.5 \mathrm{~mL}$ Folin-Ciocalteu reagent. After $3 \mathrm{~min}$, one $\mathrm{mL}$ of sodium carbonate solution $(35 \%, \mathrm{v} / \mathrm{v})$ was added to the reaction mixture, mixed, and diluted with water to a final volume of $10 \mathrm{~mL}$. The absorbance of the solution was measured at $725 \mathrm{~nm}$. The calibration curve was constructed using standard solutions of gallic acid in the range of 50 to $500 \mu \mathrm{g} \cdot \mathrm{mL}^{-1}$. The results were expressed as gallic acid equivalent (GAE) in mg.100 $\mathrm{g}^{-1}$ of oil (mg GAE $100 \mathrm{~g}^{-1}$ oil).

\subsection{Evaluation of radical scavenging activity}

Given the complex properties of the oil, there is no single method that fully reflects the antioxidant profile of a sample, making the data compiled to date difficult to compare and interpret. In our study, radical scavenging activity (RSA) of the oil samples was assayed using both DPPH and ABTS methods. In the DPPH method, both oil samples and methanolic extracts were assayed; for the ABST method, the methanolic extracts were assayed.

A methanolic extract was extracted from $2 \mathrm{~g}$ of each of the Sacha Inchi oil samples, mixed with $1 \mathrm{~mL}$ of $\mathrm{n}$-hexane, and the mixture vigorously stirred until dissolution. Two $\mathrm{ml}$ of a methanol/water $(80: 20 \mathrm{v} / \mathrm{v})$ mixture was added to each diluted sample, followed by centrifugation ( $5 \mathrm{~min} 5000 \mathrm{rpm}$ ). The extraction was repeated twice and the methanolic extracts were combined. 


\subsubsection{DPPH assay}

The DPPH assay of radical scavenging activity was performed according to the procedure reported by Morales and Jiménez-Pérez (2001). For the methanolic extract assay, an aliquot of $1 \mathrm{~mL}$ methanolic extract of Sacha Inchi oil was added to $4 \mathrm{ml}$ of DPPH $\left(40 \mathrm{mg} \cdot \mathrm{L}^{-1}\right)$ in ethyl acetate. The mixture was vigorously stirred for a few seconds and kept in the dark for $1 \mathrm{~h}$. Absorbance was measured at $515 \mathrm{~nm}$ against ethyl acetate. For Sacha Inchi oil samples, $1 \mathrm{~g}$ of oil was diluted with $10 \mathrm{~mL}$ of $\mathrm{n}$-hexane and an aliquote of $1 \mathrm{~mL}$ of the dilution was added to $4 \mathrm{~mL}$ of DPPH solution which was previously diluted with ethyl acetate (Minioti and Georgiou, 2010). In both measurements, methanolic solutions of gallic acid were used for calibration ranging from 5 to $60 \mathrm{mM}$

$$
\mathrm{y}=-0.0939 \mathrm{x}+0.086
$$

being $\mathrm{x}=$ absorbance and $\mathrm{y}=\mu \mathrm{mol} \mathrm{GAE} \cdot \mathrm{mL}^{-1}$ sample.

The results were expressed as mmol equivalent of gallic acid per $\mathrm{kg}$ of sample.

\subsubsection{ABTS assay}

The ABTS assay of the radical scavenging activity of the methanolic extracts of the oil samples was performed following the standard procedure described by Jimenez-Escrig et al., (2003). Briefly, ABTS was produced by reacting a $7 \mathrm{mM}$ ABTS stock solution with $2.45 \mathrm{mM}$ potassium persulfate and allowing the mixture to stand in the dark at room temperature for about $12-16 \mathrm{~h}$ before use. The $\mathrm{ABTS}^{++}$solution was diluted with $5 \mathrm{mM}$ phosphate buffered saline ( $\mathrm{pH}$ 7.4) to an absorbance of $0.70 \pm 0.02$ at $745 \mathrm{~nm}$. An aliqote of $1 \mathrm{~mL}$ methanolic extract was added to $4 \mathrm{~mL}$ of a diluted $\mathrm{ABTS}^{++}$ solution and an absorbance reading was taken $1 \mathrm{~h}$ later. Methanolic solutions of gallic acid ranging from 5 to $60 \mathrm{mM}$ were used for calibration

$$
y=-0.0998 x+0.0394
$$

being $\mathrm{x}=$ absorbance and $\mathrm{y}=\mu \mathrm{mol} \mathrm{GAE} \cdot \mathrm{mL}^{-1}$ sample.

The results were expressed as mmol equivalents of gallic acid per $\mathrm{kg}$ of sample.

\subsection{Evaluation of storage stability}

The storage stability of Sacha Inchi oil was determined by acid value (AV) and peroxide value (PV) analyses during long time storage. Researchers have shown that light and temperature are important factors contributing to lipid oxidation (Fereidoon, 2005; Stark et al., 2000). The total amount of Sacha Inchi oil was stored for 12 months in colorless and green bottles with polyethylene sealing lids. Three of each type of bottle were then stored at three different temperature: $4{ }^{\circ} \mathrm{C}, 20^{\circ} \mathrm{C}$ and $30^{\circ} \mathrm{C}$. Analyses were conducted at 2-month intervals for $\mathrm{AV}$ and $\mathrm{PV}$.

\subsection{Statistical analysis}

All measurements were repeated at least three times. The values of the different parameters were expressed as mean \pm standard deviation (SD). The data were analyzed using SPSS software (SPSS. 16.0, USA) and SigmaPlot software (SigmaPlot. 10.0, USA) for Windows.

\section{RESULTS AND DISCUSION}

\subsection{Physicochemical Characteristics}

The Physicochemical Characteristics of Sacha Inchi oil from Xishuangbanna and Peru are shown in Table 1. Acid value $\left(1.79 \pm 0.004 \mathrm{mg} \mathrm{KOH} \cdot \mathrm{g}^{-1}\right.$ oil) and peroxide value $\left(1.846 \pm 0.067 \mathrm{meq} \mathrm{O}_{2} \cdot \mathrm{kg}^{-1}\right.$ oil $)$ are within the limits $\left(4.0 \mathrm{mg} \mathrm{KOH} \cdot \mathrm{g}^{-1}\right.$ oil and $15 \mathrm{meq}$ $\mathrm{O}_{2} \cdot \mathrm{kg}^{-1}$ oil, respectively) established by The Codex Alimentarius Commission for cold-pressed and nonrefined oil (FAO, 1999). The saponification value and iodine value from Xishuangbanna are slightly lower than the values from Peru. Moisture and volatile compound contents, unsaponification matter, insoluble impurities, refractive index, with specific extinction of Sacha Inchi oil were first characterized.

\subsection{Fatty acid composition}

The fatty acid profile of Sacha Inchi oil was analyzed using GC-FID. Peak identification was obtained by conjunction with pure standard FAMEs.

\begin{tabular}{|c|c|c|}
\hline Physicochemical characteristics & Present study & Gutiérrez $^{\text {b }}$ \\
\hline Acid value (mg KOH·g-1 oil) & $1.79 \pm 0.004$ & ND \\
\hline Peroxide value (meq $\mathrm{O}_{2} \cdot \mathrm{kg}^{-1}$ oil) & $1.85 \pm 0.06$ & ND \\
\hline $\begin{array}{l}\text { Saponification value (mg } \\
\mathrm{KOH} \cdot \mathrm{g}^{-1} \text { oil) }\end{array}$ & $183.78 \pm 1.46$ & $185.2 \pm 0.5$ \\
\hline Unsaponifiable matter $\left(\mathrm{g} \cdot \mathrm{kg}^{-1}\right)$ & $5.03 \pm 0.21$ & ND \\
\hline Iodine value $\left(\mathrm{g} \mathrm{I}_{2} \cdot 100 \mathrm{~g}^{-1}\right)$ & $187.40 \pm 1.61$ & $193.1 \pm 1.0$ \\
\hline $\begin{array}{l}\text { Moisture and volatile } \\
\text { compound content (\%) }\end{array}$ & $0.014 \pm 0.002$ & ND \\
\hline Insoluble impurities (\%) & $0.013 \pm 0.01$ & ND \\
\hline Refractive index $\left(\mathrm{n}^{40}\right)$ & $1.475 \pm 0.001$ & ND \\
\hline specific $\quad E_{1 \mathrm{~cm}}^{1 \%}$ at $232 \mathrm{~nm}$ & $2.98 \pm 0.04$ & ND \\
\hline extinction $\quad \mathrm{E}^{1 \%}{ }_{1 \mathrm{~cm}}$ at $270 \mathrm{~nm}$ & $0.30 \pm 0.01$ & ND \\
\hline
\end{tabular}

TABLE 1. Physicochemical characterization of Sacha Inchi oil ${ }^{\text {a }}$

${ }^{a}$ Means \pm SD of three determinations.

${ }^{\mathrm{b}}$ Gutiérrez et al., 2011.

ND: Not detected. 
TABLE 2. The comparisons of fatty acids among Sacha Inchi oil and other common vegetable oils

\begin{tabular}{lccccccccc}
\hline Fatty acids & Palmitic & Stearic & Oleic & Linoleic & Linolenic & MUFAs $^{\mathbf{a}}$ & PUFAs $^{\mathbf{b}}$ & UFAs/SFAs $^{\mathbf{c}}$ & Reference $^{\text {(n) }}$ \\
\hline Sacha Inchi & 4 & 3 & 9 & 40 & 44 & 9 & 84 & 13 & \\
Sacha Inchi' & 4 & 3 & 9 & 36 & 47 & 9 & 83 & 13 & Fanali et al., 2011 \\
Soybean & 11 & 4 & 23 & 54 & 8 & 23 & 62 & 5.7 & Dyer et al., 2008 \\
Sunflower & 6 & 4 & 29 & 58 & ND & 29 & 58 & 8.7 & Dyer et al., 2008 \\
Olive & 12 & 3 & 70 & 10 & ND & 70 & 10 & 5.3 & Dyer et al., 2008 \\
Linseed & 6 & 2 & 19 & 24 & 47 & 19 & 66 & 11 & Dyer et al., 2008 \\
Peanut & 9 & 3 & 52 & 32 & ND & 52 & 32 & 7.0 & Ozcan, 2010 \\
\hline
\end{tabular}

${ }^{a}$ Monounsaturated fatty acid.

${ }^{b}$ Polyunsaturated fatty acid.

'Unsaturated fatty acids ratio/Saturated fatty acids.

${ }^{\mathrm{d} S}$ Sacha Inchi oil from Peru.

ND: Not detected.

The chromatography results showed that the major fatty acids identified in Sacha Inchi oil are palmitic acid $(4.40 \pm 0.34 \%)$, stearic acid $(3.21 \pm 0.06 \%)$, oleic acid $(9.29 \pm 0.32 \%)$, linoleic acid $(39.57 \pm 0.20 \%)$, and linolenic acid $(43.52 \pm 0.92 \%)$. Similar to the reported fatty acid data on Sacha Inchi oil from Peru, Sacha Inchi oil from Xishuangbanna is also dominated by linolenic and linoleic acids. The remarkably high content of linolenic acid $(43.52 \%)$ makes the oil especially important as an alternative plant-based $\omega-3$ source in the diet, especially in China. According to a survey on dietary intake across China, people in the Northwest region receive sufficient $\omega-3$ fatty acids from perilla seed oil, but in other regions the $\omega-3 / \omega-6$ fatty acid is lower than the World Health Organization (WHO) recommended ratio of 1:4. Therefore, it is important for people to increase $\omega-3$ fatty acid intake for optimum health (Zhang, 2004). The fatty acid compositions of Sacha Inchi oil from Xishuangbana and Peru are similar (Table 2), with a much higher content of linolenic acid than other commonly consumed vegetable oils such as soybean and peanut oil (Fanali et al., 2011; Dyer et al., 2008; Ozcan., 2010). Therefore, Sacha Inchi oil has great potential to serve as an alternative linolenic acid source in the diet either as an edible oil or through nutraceutical supplements.

\subsection{Tocopherol composition}

Tocopherols are an important minor component in oil that may be anti-oxidative and slow down the process of oxidation (Kamal-Eldin et al., 1996). Oils with higher levels of tocopherols are expected to exhibit greater oxidative stability. Total tocopherols in Sacha Inchi oil from Xishuangbanna was $161.87 \pm 0.85 \mathrm{mg} \cdot 100 \mathrm{~g}^{-1}$ (Table 2), a little lower than in Sacha Inchi oil from Peru, but higher than in most other edible oils (Fanali, et al., 2011; GliszczyńskaŚwigło and Sikorska, 2004). More importantly, most of the tocopherol content detected in Sacha Inchi oil is $\gamma$-tocopherol whereas $\alpha$-tocopherol is predominant

TABLE 3. Comparison of Tocopherols in Sacha Inchi oil and other vegetable oils (mg.100 $\mathrm{g}^{-1}$ oil)

\begin{tabular}{lccccl}
\hline & $\alpha$-tocopherol & $\gamma$-tocopherol & $\delta$-tocopherol & Total Tocopherol & Reference \\
\hline Sacha Inchi & ND & 105.21 & 56.66 & 161.87 & \\
Sacha Inchi $^{a}$ & 0.4 & 125.70 & 86.90 & 213.00 & Fanali, et al., 2011 \\
Soybean & 15.34 & 50.40 & 18.85 & 84.59 & Gliszczyńska-Świgło and Sikorska, 2004 \\
Sunflower & 59.13 & 2.54 & 0.87 & 62.54 & Gliszczyńska-Świgło and Sikorska, 2004 \\
Peanut & 10.02 & 11.20 & 1.19 & 22.41 & Gliszczyńska-Świgło and Sikorska, 2004 \\
Olive & 16.08 & 1.25 & 0.13 & 17.46 & Gliszczyńska-Świgło and Sikorska, 2004 \\
Grapeseed & 10.06 & 1.71 & 0.39 & 12.16 & Gliszczyńska-Świgło and Sikorska, 2004 \\
Corn & 2.04 & 5.83 & 2.94 & 10.81 & Gliszczyńska-Świgło and Sikorska, 2004 \\
Rapeseed & 1.95 & 2.98 & 1.19 & 6.12 & Gliszczyńska-Świgło and Sikorska, 2004 \\
\hline
\end{tabular}

a Sacha Inchi oil from Peru.

ND: Not detected. 
in olive oil and sunflower oil. Tocopherols are the most efficient antioxidant of a lipidic nature in the human diet and it is important in the biosynthesis of related proteins (Procida et al., 2013). Research has also shown that $\alpha$-tocopherol is more efficient than $\gamma$-tocopherol in inhibiting the formation of both hydroxyl- and ketodiene-derivatives at $10 \mathrm{ppm}$, but this order of efficiency was reversed at $100 \mathrm{ppm}$ and higher concentrations (Makinen et al., 2000).

\subsection{Total phenols}

The total phenolic compound content of Sacha Inchi oil from Xishuangbanna was determined using the Folin-Ciocalteu technique. The concentration of phenols was $6.58 \pm 0.27 \mathrm{mg} \cdot 100 \mathrm{~g}^{-1}$ of oil expressed as GAE, similar to the reported value of Sacha Inchi oil from Peru (6.2 mg.100 g $\mathrm{g}^{-1}$ ) (Fanali et al., 2011). According to a report by Valavanidis et al. (2004), among edible oils, extra virgin olive oil has the highest total phenolic content with a range of $17-21 \mathrm{mg}$ GAE $100 \mathrm{~g}^{-1}$. Soybean oil has mid-range levels of total phenolics at $6-8 \mathrm{mg} 100 \cdot \mathrm{g}^{-1}$. Sunflower oil has even lower levels with a range of $3-4 \mathrm{mg} \cdot 100 \mathrm{~g} \mathrm{~g}^{-1}$, and corn oil samples contained less than $1 \mathrm{mg} \cdot \mathrm{kg}^{-1}$. Sacha Inchi oil from Xishuangbanna appears to have similar levels of total phenolics as soybean oil. Polyphenols are good for the oil's oxidative stability of polyunsaturated fatty acids imparting the characteristic flavor to the oil. Moreover, many polyphenols have beneficial effects on some common diseases including hypertension and atherosclerosis and play roles in the prevention of certain cancers and modification of immune responses (Luaces et al., 2007).

\subsection{Evaluation of radical scavenging activity}

The radical scavenging activity (RSA) of the analyzed methanol extract of Sacha Inchi oil samples was $12.82 \pm 0.60$ and $8.25 \pm 0.50 \mathrm{mM}$ gallic acid $\cdot \mathrm{kg}^{-1}$ Sacha Inchi oil for DPPH and ABTS methods, respectively. For total Sacha Inchi oil, the total antioxidant activity (TAC) was $133.42 \pm 3.63 \mathrm{mM}$ gallic acid $\cdot \mathrm{kg}^{-1}$ Sacha Inchi oil measured by the DPPH method. Results from the DPPH assay in total oil were much higher than those in the hydrophilic fraction indicating that the main component responsible for antioxidant activity is within the hypdophobic fraction. The high content of tocopherols could play a major antioxidant role in Sacha Inchi oil, or in synergy with phenolics (Espin et al., 2000). The exact roles of tocopherols and phenolics in the antioxidative activity of the oil are worth further study. In a similar study of the total antioxidant capacity of Greek olive oil, Minioti et al. (2010) showed that antioxidant capacities among 50 samples in the hydrophilic fraction were between $1.29-9.95 \mathrm{mM}$ (DPPH) and 5.42-22.5 mM (ABTS) gallic acid/ $\mathrm{kg}$ oil. While in total oil, the antioxidant activity ranged from $77-177 \mathrm{mM} \cdot \mathrm{kg}^{-1}$ as assessed by the DPPH method. The mean antioxidant capacity values for DPPH and ABTS in the hydrophilic fraction are $5.4 \pm 2.2$ and $13.1 \pm 4.2 \mathrm{mM}$ gallic acid $\cdot \mathrm{kg}^{-1}$ oil

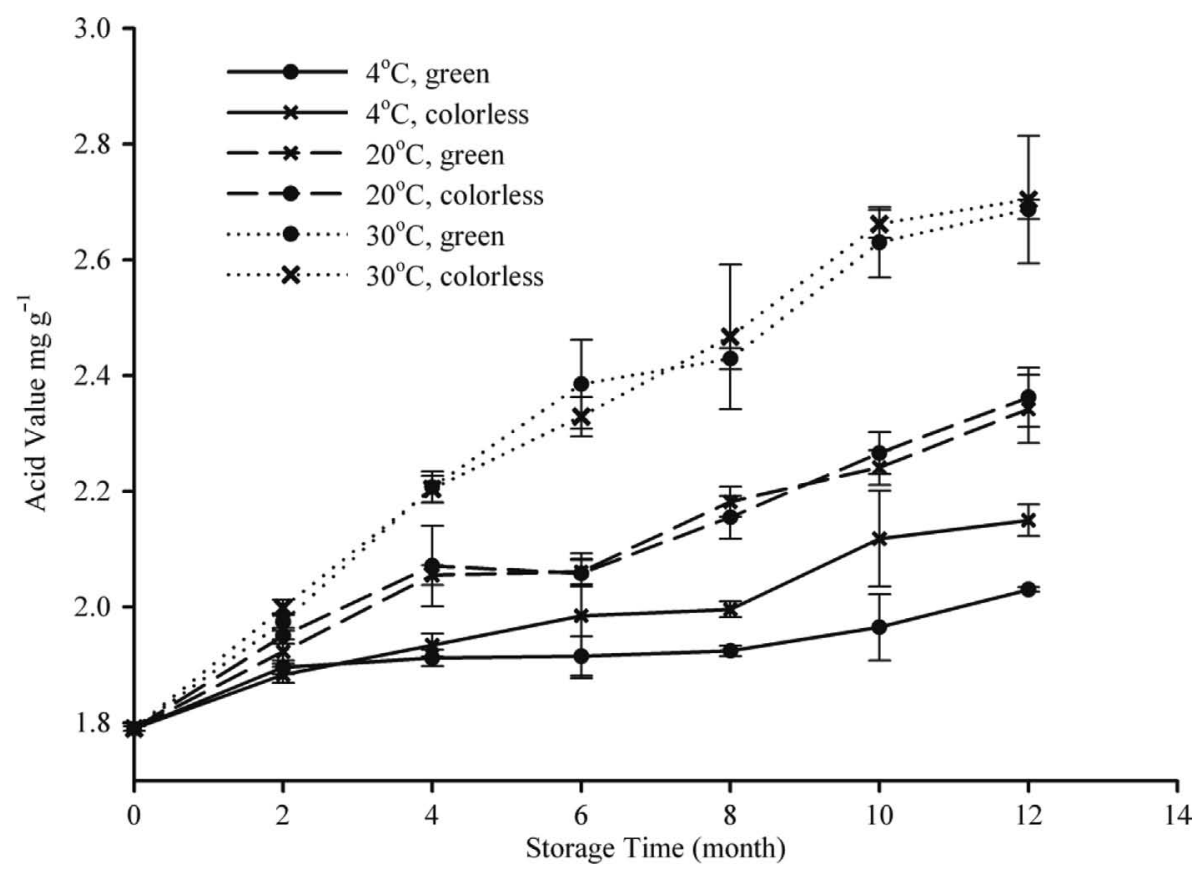

FIG.1. Changes in acid values (AV) of Sacha Inchi oil during 12 months of storage. Oil samples were stored in colorless and green bottles at $4{ }^{\circ} \mathrm{C}, 20^{\circ} \mathrm{C}$ and $30^{\circ} \mathrm{C}$. Values are the means of triplicate determinations $\pm \mathrm{SD}$. 


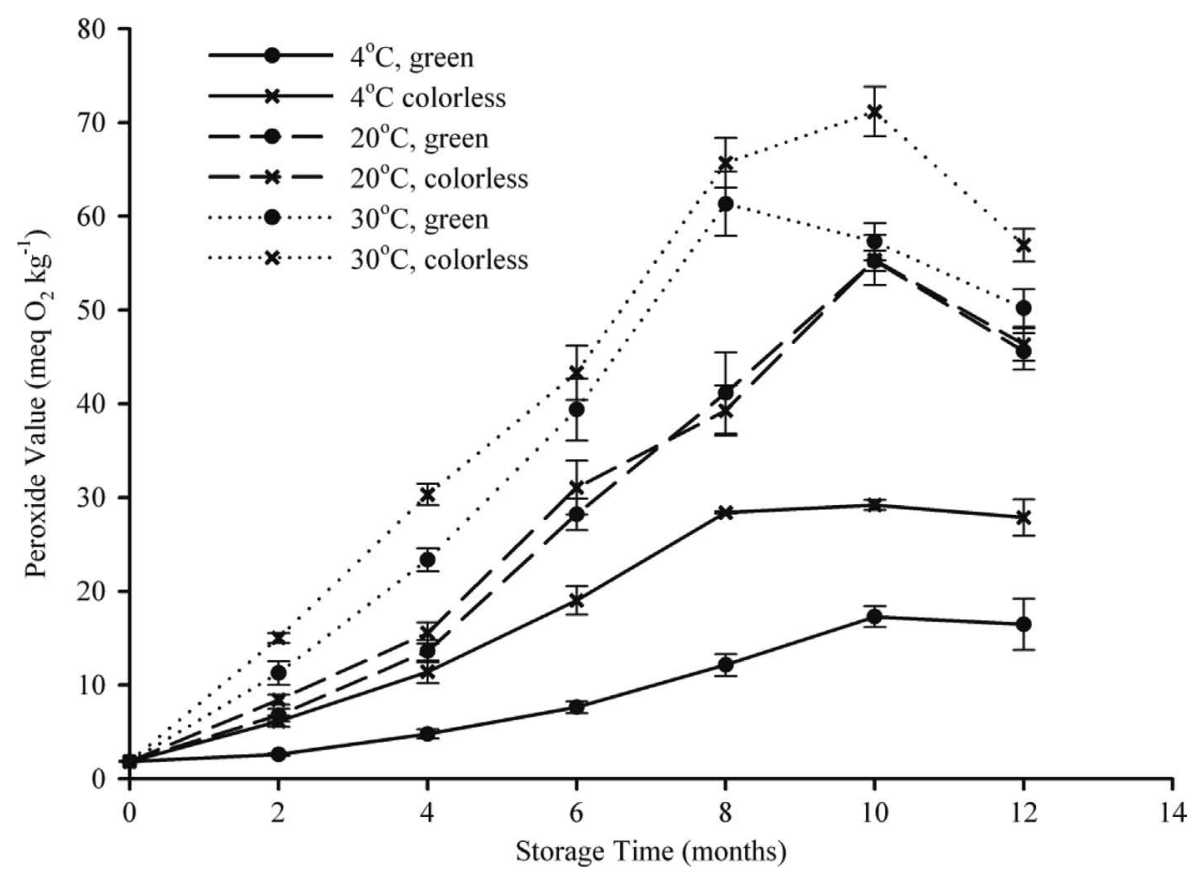

FIG. 2. Changes in peroxide values (PV) of Sacha Inchi oil during 12 months of storage. Oil samples were stored in colorless and green bottles at $4{ }^{\circ} \mathrm{C}, 20^{\circ} \mathrm{C}$ and $30^{\circ} \mathrm{C}$. Values are the means of triplicate determinations $\pm \mathrm{SD}$.

while values in DPPH in total olive oil is $116.4 \mathrm{Mm}$ gallic acid $\cdot \mathrm{kg}^{-1}$ oil. The RSA of Sacha Inchi oil appears to be higher than in most Greek virgin olive oils. For Sacha Inchi oil, the total phenolics together with tocopherols not only act as antioxidants but also bring more health benefits beyond essential fatty acids. The health benefits associated with this high radical scavenging activity are worth further investigation.

\subsection{Evaluation of storage stability}

The storage stability of Sacha Inchi oil was evaluated by acid value (AV) and peroxide value (PV) analyses during 12 months of storage. The formation of free fatty acids is an important measure of food rancidity, which leads to a number of effects such as hydrolyzed and oxidation rancidity. Acid value is a principal indicator of lipid rancidity, the value of the oil samples ranged from $1.790 \pm 0.004$ to $2.704 \pm 0.110 \mathrm{mg} \mathrm{KOH} \cdot \mathrm{g}^{-1}$ oil during the entire storage period (Figure 1). In addition, acid value increased faster at a higher temperature, but no significant difference in AV was observed between colorless and green bottles. This result shows that temperature is a major parameter leading to the rancidity of Sacha Inchi oil.

Peroxide value (PV) is the most common measurement of lipid oxidation. As a measurement of hydroperoxide formation, it has been recognized as a useful index for early stages of oxidation. Usually, in a typical test, PV reaches a maximum value during the process of oxidation followed by a decrease. In Sacha Inchi oil, PV increased steadily in the first 10 months and then plateaued (Figure 2). Compared with oil samples stored in colorless bottles, the samples stored in green bottles showed higher oxidative stability, and the oil samples stored at $4{ }^{\circ} \mathrm{C}$ showed the highest oxidative stability. Notably, PV reached a value of $15 \mathrm{meq} \mathrm{O}_{2} \cdot \mathrm{kg}^{-1}$ oil at about 9 months (Figure 1A). It is generally accepted that PV of oil is not more than $15 \mathrm{meq} \mathrm{O}_{2} \cdot \mathrm{kg}^{-1}$ oil for safe consumption (FAO, 1999). The PV analyses suggest that Sacha Inchi oil from Xishuangbanna has a stable shelf life of about 9 months in green bottles at $4{ }^{\circ} \mathrm{C}$. The oil remaining stable may be attributed to high levels of tocopherols and phenolics as natural antioxidants. This is the first time the oxidative stability of Sacha Inchi oil has been evaluated and the results may give rise to further research and additional applications of the oil.

\section{CONCLUSIONS}

The initial characterization of Sacha Inchi oil showed that it is a highly nutritious plant-based edible oil with unique fatty acid profiles, excellent radical scavenging activity and storage stability. The remarkably high content of linolenic acid makes it a rich source of $\omega-3$ fatty acids. Sacha Inchi oil has great potential to serve as an alternative plant-based $\omega-3$ PUFAs in the diet to help achieve a balanced 
$\omega-3 / \omega-6$ fatty acid intake. Tocopherols and total phenolic compounds in the oil might also add more nutritional value as antioxidants and are probably the main components responsible for the oxidative stability of Sacha Inchi oil. The relatively good storage stability of the oil suggests that it could be consumed as an edible oil with a relatively long shelf-life without additives. The results from this study will help guide further investigation on the health benefits of SachaInchi oil for the population and the development of better edible oil products and nutraceuticals for the market.

\section{ACKNOWLEDGMENTS}

The authors gratefully acknowledge the financial support from "CAS Key Laboratory of Tropical Plant Resource and Sustainable Use, Xishuangbanna Tropical Botanical Garden, Chinese Academy of Sciences" (KSCX2-EW-Z-15). The authors gratefully acknowledge the technical support of Mr. Yang Jun and Mrs. Wang Wenhui from the Research Center for Analysis and Measurement at Kunming University of Science and Technology.

\section{REFERENCES}

AOCS. 2009. Official methods and recommended practices of the AOCS (6th ed.). Champaign, IL, USA.

Cao M, Zou XM, Warren M, Zhu H. 2006. Tropical Forests of Xishuangbanna, China. Biotropica 38, 306-309.

Cai ZQ, Jiao DY, Tang SX, Dao XS, Lei YB, Cai CT. 2012. Leaf photosynthesis, growth, and seed chemicals of Sacha Inchi plants cultivated along an altitude gradient. Crop Sci. 52, 1859-1867.

Cai ZQ, Yang Q, Tang SX, Dao XS. 2011. Nutritional evaluation in seeds of woody oil crop Plukenetia volubilis Linneo. Acta Nutrimenta Sinica. 33, 193-195.

Christie WW. 2003. Isolation, Separation, Identification and Structural Analysis of Lipids. The Oily Press. Bridgwater, England.

Do Prado IM, Giufrida WM, Alvarez VH, Cabral VF, QuispeCondori S, Saldana MDA, Cardozo L. 2011. Phase equilibrium measurements of Sacha Inchi oil (Plukenetia volubilis) and $\mathrm{CO}_{2}$ at high pressures. J. Am. Oil. Chem. Soc. 88, 1263-1269.

Dyer JM, Stymne S, Green AG, Carlsson AS. 2008. High-value oils from plants. Plant J. 54, 640-655.

Espin JC, Soler-Rivas C, Wichers HJ. 2000. Characterization of the total free radical scavenger capacity of vegetable oils and oil fractions using 2, 2-diphellyl-1-picrylhydrazyl radical. J. Agric. Food. Chem. 48, 648-656.

Fanali C, Dugo L, Cacciola F, Beccaria M, Grasso S, Dacha M, Dugo P, Mondello L. 2011. Chemical characterization of Sacha Inchi (Plukenetia volubilis L.) Oil. J. Agric. Food. Chem. 59, 13043-13049.

FAO/WHO 1999. The Codex Alimentarius Commission. Codex standard for named vegetable oils. Available from: http://www.codexalimentarius.org/ (Last visited 1st March 2013).

Fereidoon S. 2005. Quality assurance of fats and oils. In Fereidoon Shahidi, Bailey's Industrial Oil and Fat Products (6th ed.) (pp. 565-575). John Wiley \& Sons Inc. Manhattan, USA.

Gimeno E, Calero E, Castellote A, Lamuela-Raventos RM, de la Torre MC, Lopez-Sabater MC. 2000. Simultaneous determination of alpha-tocopherol and beta-carotene in olive oil by reversed-phase high-performance liquid chromatography. J. Chromatogr. A. 881, 255-259.

Gliszczyńska-Swigło A, Sikorska E. 2004. Simple reversedphase liquid chromatography method for determination of tocopherols in edible plant oils. J. Chromatogr. A. 1048, 195-198.

Guillén MD, Ruiz A, Cabo N, Chirinos R, Pascual G. 2003. Characterization of Sacha Inchi (Plukenetia volubilis L.) oil by FTIR spectroscopy and H-1 NMR. comparison with linseed oil. J. Am. Oil. Chem. Soc. 80, 755-762.

Gutiérrez LF, Rosada LM, Jiménez A. 2011. Chemical composition of Sacha Inchi (Plukenetia volubilis L.) seeds and characteristics of their lipid fraction. Grasas Aceites 62, 76-83.

Hamaker BR, Valles C, Gilman R, Hardmeier RM, Clark D, Garcia HH, Gonzales AE, Kohlstad I, Castro M, Valdivia R, Rodriguez T, Lescano M. 1992. Anino-acid and fatty-acid profiles of the Incha peanut (Plukenetia volubilis). Cereal Chem. 69, 461-463.

Hrncirik K, Fritsche S. 2004. Comparability and reliability of different techniques for the determination of phenolic compounds in virgin olive. Eur. J. Lipid. Sci. Technol. 106, 540-549.

Jimenez-Escrig A, Dragsted LO, Daneshvar B, Pulido R, Saura-Calixto F. 2003. In vitro antioxidant activities of edible artichoke (Cynara scolymus L) and effect on biomarkers of antioxidants in rats. J. Agric. Food Chem. 51, $5540-5545$

Krivankova B, Polesny Z, Lojka B, Lojkova J, Banout J, Preininger D. 2007. Sacha Inchi (Plukenetia volubilis, Euphorbiaceae): a promising oilseed crop from Peruvian Amazon. In Conference on International Agricultural Research and Development. University of Kassel, Germany.

Luaces P, Romero C, Gutierrez F, Sanz C, Perez AG. 2007. Contribution of olive seed to the phenolic profile and related quality parameters of virgin olive oil. J. Sci. Food Agric. 87, 2721-2727.

Makinen M, Kamal-Eldin A, Lampi AM, Hopia A. 2000. Effects of alpha- and gamma-tocopherols on formation of hydroperoxides and two decomposition products from methyl linoleate. J. Am. Oil. Chem .Soc. 77, 801-806.

Maurer NE, Hatta-Sakoda B, Pascual-Chagman G, RodriguezSaona LE. 2012. Characterization and authentication of a novel vegetable source of omega-3 fatty acids, Sacha Inchi (Plukenetia volubilis L.) oil. Food Chem. 134, 1173-1180.

Minioti KS, Georgiou CA. 2010. Comparison of different tests used in mapping the Greek virgin olive oil production for the determination of its total antioxidant capacity. Grasas Aceites 61, 45-51.

Morales FJ, Jiménez-Pérez S. 2001. Free radical scavenging capacity of Maillard reaction products as related to colour and fluorescence. Food Chem. 72, 119-125.

Myers N, Mittermeier RA, Mittermeier CG, da Fonseca GAB, Kent J. 2000. Biodiversity hotspots for conservation priorities. Nature 403, 853-858.

Ni-Eidhin D, Burke J, O'Beirne D. 2003. Oxidative stability of omega-3 rich camelina oil and camelina oil-based spread compared with plant and fish oils and sunflower spread. J. Food Sci. 68, 345-353.

Ozcan MM. 2010. Some nutritional characteristics of kernel and oil of peanut (Arachis hypogaea L.). J. Oleo Sci. $\mathbf{5 9}, 1-5$.

Pietrowski BN, Tahergorabi R, Matak KE, Tou JC, Jaczynski J. 2011. Chemical properties of surimi sea food nutrified with omega-3 rich oils. Food Chem. 129, 912-919.

Procida G, Stancher B, Cateni F, Zacchigna M. 2013. Chemical composition and functional characterisation of commercial pumpkin seed oil. J. Sci. Food Agric. 93, 1035-1041.

Rymer C, Givens DI. 2005. n-3 fatty acid enrichment of edible tissue of poultry: A review. Lipids 40, 121-130.

Rubio-Rodriguez N, Beltran S, Jaime IM, de Diego S, Sanz MT, Carallido JR. 2010. Production of omega-3 polyunsaturated fatty acid concentrates: A review. Innov. Food Sci. Emerg. 11, 1-12. 
Chemical composition and oxidative evolution of Sacha Inchi (Plukentia volubilis L.) oil from Xishuangbanna (China) 9

Semino CA, Rojas FC, Zapata ES. 2008. Protocolo del cultivo de Sacha Inchi. (Plukenetia volubilis L.). La Merced, Peru.

Stark C, McNeil DL, Savage GP. 2000. The effect of storage conditions on the stability of peroxide values of New Zealandgrown walnuts. P. Nutr. Soc. N. 25, 43-54.

Valavanidis A, Nisiotou C, Papageorgiou Y, Kremli I, Satravelas $\mathrm{N}$, Zinieris N, Zygalaki H. 2004. Comparison of the radical scavenging potential of polar and lipidic fractions of olive oil and other vegetable oils under normal conditions and after thermal treatment. J. Agric. Food Chem. 52, 2358-2365.

Venegas-Calderón M, Sayanova O, Napier JA. 2010. An alternative to fish oils: Metabolic engineering of oil seed crops to produce omega-3 long chain polyunsaturated fatty acids. Prog. Lipid Res. 49, 108-119.

Zhang J, Wang CR, Gao JQ, Li XW, Chen JS. 2004. Study on dietary lipid intakes in Chinese residents. Acta Nutrmenta Sinica 26, 167-171. 